\title{
ИССЛЕДОВАНИЕ КИНЕТИКИ ОБРАЗОВАНИЯ НИТРОЗНЫХ РАДИКАЛОВ В СИСТЕМЕ ОТВЕРЖДЕНИЯ БУТИЛКАУЧУКА В ПРИСУТСТВИИ ПРОСТРАНСТВЕННО-ЗАТРУДНЁННОГО 2,4,6-ТРИ-трет-БУТИЛФЕНОЛА
}

\author{
Э. Х. Афиатуллов, Т. А. Чапко, Л.Н. Гурьева
}

\begin{abstract}
ЭНСАР ХАЛИУЛЛОВИЧ АФИАТУЛЛОВ - кадидат технических наук, заместитель генерального директора по научной работе АО «Научно-исследовательский институт полимерных материалов». Область научных интересов - разработка и изучение свойств компонентов и полимерных композиционных материалов различного назначения, анализ физико-химических свойств их компонентов.
\end{abstract}

ТАИСИЯ АЛЕКСЕЕВНА ЧАПКО - кандидат химических наук, начальник отдела АО «Научноисследовательский институт полимерных материалов». Область научных интересов - аналитическая химия, анализ физико-химических свойств компонентов полимерных композиционных материалов.

ЛЮДМИЛА НИКОЛАЕВНА ГУРЬЕВА - инженер АО «Научно-исследовательский институт полимерных материалов». Область научных интересов - исследование компонентов полимерных композиционных материалов с применением современных физико-химических методов анализа.

E-mailsferus83@mail.ru.

614101, г. Пермь, ул. Чистопольская, 16, АО «Научно-исследовательский институт полимерных материалов».

Изучена кинетика активности системы отверждения бутилкаучука (БК) без антиоксиданта П-23 и в его присутствии в разном количестве при температурах 55 и $80^{\circ} \mathrm{C}$. На основании полученных данных установлено, что индукционный период вулканизации образиов БК в присутствии пространственно-затруднённого фенола выше, чем у образиов без фенола и с повышением температуры скорость вулканизаиии каучука увеличивается, что обусловлено возрастанием скорости инициирования.

Ключевые слова: кинетика, механизм реакции, вулканизация, бутилкаучук, нитрозный радикал, пространственно-затрудненный фенол, 2,4,6-три-трет-бутилфенол.

\section{RESEARCH OF THE KINETICS OF THE FORMATION OF NITROS RADICALS IN THE CURING SYSTEM BUTYL RUBBER IN THE PRESENCE OF SPATIALLY HINDERED 2,4,6-TRITERTBUTYLPHENOL}

\author{
E.H. Afiatullov, T.A. Chapko, L.N. Gur'eva
}

16. Chistopolskaya st., Perm, 614101, Russia. JSC "Research Institute of Polymeric Materials”.

The kinetics of the activity of the curing system for butyl rubber (BR) without an antioxidant P-23 and in its presence in various amounts at temperatures of 55 and $80^{\circ} \mathrm{C}$ has been studied. On the basis of the data obtained, 
it is determined that the induction period of the vulcanization of BR samples in the presence of spatially hindered phenol is higher than in samples without phenol and with increasing temperature, the vulcanization rate of rubber increases, which is caused by an increase in the initiation rate.

Key words: kinetics, reaction mechanism, vulcanization, butyl rubber, nitros radical, sterically hindered phenol, 2,4,6-tri-tert-butylphenol.

Одним из направлений в создании композиционного материала является использование в качестве связующего высокомолекулярного пластифицированного бутилкаучука (БК), обеспечивающего получение высоких физико-механических свойств даже при небольшом содержании каучука, обладающего рядом достоинств по сравнению с другими применяемыми эластомерными связующими.

В практике производства промышленного продукта, содержащего этот материал (БК), наряду с другими используется система отверждения, в которой фактическим вулканизирующим агентом БК в исследуемой системе при окислительновосстановительной системе вулканизации является продукт окисления парахинондиоксима (ПХД) двуокисью марганца $\left(\mathrm{MnO}_{2}\right)$ - парадинитрозобензол (п-ДНБ), сшивающий молекулы каучука.

Для предотвращени я преждевременного отверждения БК необходимо вводить ингибиторы процесса отверждения. В качестве ингибитора может выступать соединение, которое удовлетворяет следующим условиям:

1. Ингибитор, реагируя с активным центром, должен давать продукт (чаще всего это радикал), который не участвует в продолжении роста цепи. Только в этом случае ингибитор, вступая в реакцию, обрывает цепь.

2. Ингибитор должен обладать высокой реакционной способностью по отношению, по крайней мере, к одному из активных центров, ведущих цепь. Только тогда он успешно конкурирует с реагентами, вступающими с активными центрами в акты продолжения роста цепи.

3. Сам ингибитор и образующиеся из него в процессе реакции продукты не должны обладать заметным инициирующим действием, так как в этом случае скорость реакции будет увеличиваться за счет роста скорости инициирования [1].

В данном эксперименте использовался антиоксидант 2,4,6-тритретбутилфенол (П-23), являющийся ароматическим соединением со сравнительно слабой $\mathrm{O}-\mathrm{H}-$ связью.
Производство антиоксиданта является многостадийным процессом синтеза, основой которого является гомогенное или гетерогенное каталитическое алкилирование фенола изобутиленом с последующей ректификацией продуктов синтеза и очисткой методом многократной перекристаллизации. Каждая стадия может оказывать влияние на качество и чистоту получаемого продукта.

Применяя П-23 можно регулировать продолжительность индукционного периода вулканизации БК.

Обширный материал по вулканизации БК хинондиоксимами интерпретирует вулканизацию через стадию образования п-ДНБ, осуществляющего сшивку по изопреновому звену каучука $[2,3]$. Отверждение каучука протекает по радикальному механизму. В связи с этим для такой оценки использован метод электронного парамагнитного резонанса (ЭПР). В работе использовался спектрометр ESP-300 с частотой 9,8 ГГц. Условием применения метода ЭПР является наличие в исследуемой системе неспаренных электронов c соответствующими магнитными моментами. В данной системе в роли парамагнитных частиц выступают нитрозные радикалы, образующиеся в процессе вулканизации БК при окислении ПХД двуокисью марганца.

Изучалась кинетика активности системы отверждения бутилкаучука в зависимости от содержания П-23 при температурах 55 и $80{ }^{\circ} \mathrm{C}$. Для выполнения измерений готовили модельные смеси, содержащие БК и ферроценовое масло (ФМ), ПХД, $\mathrm{MnO}_{2}$ и П-23 одних и тех же партий, менялось только содержание антиоксиданта. От свежеприготовленных смесей отбирали необходимое количество для заполнения стеклянных ампул. Снимали спектры исследуемых образцов и эталона с интервалом 1 час. Вначале записывали спектр ЭПР эталонного образца на основе ультрадисперсионного детонационного алмаза (УДА), являющегося источником стабильных радикалов. Затем снимали спектры модельных смесей после термостатирования в сушильном шкафу при температурах 55 и $80{ }^{\circ} \mathrm{C}$ в течение 32 часов. Путем интегрирования находили количество образовавшихся радикалов. 


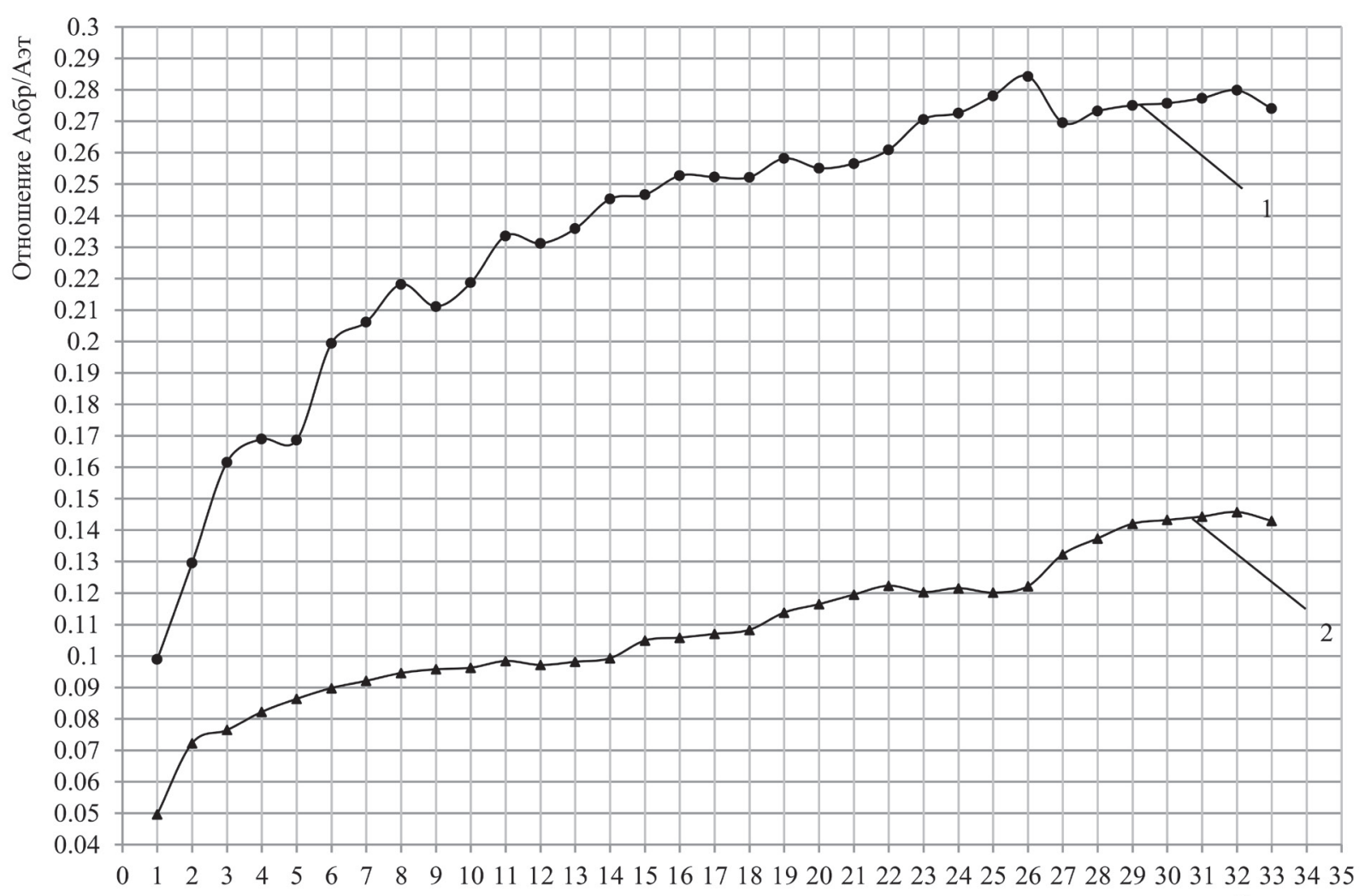

Время, час

Рис. 1. Кинетика активности системы отверждения БК в присутствии П-23 и без него при $55{ }^{\circ} \mathrm{C}$ : $1-$ без $П-23 ; 2-1,8 \%$

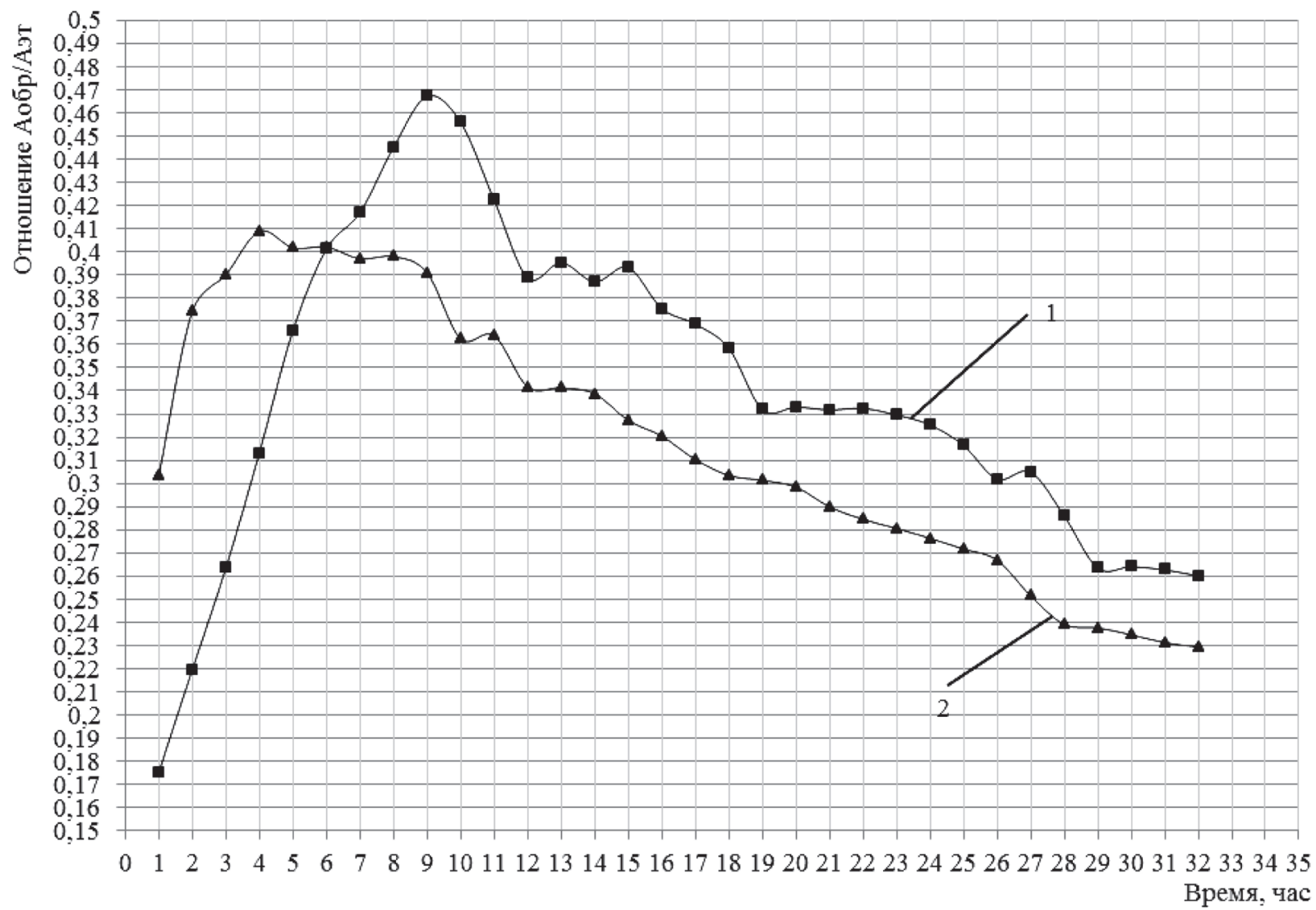

Рис. 2. Кинетика активности системы отверждения БК в присутствии П-23 и без него при $80{ }^{\circ} \mathrm{C}:$ $1-1,8 \% ; 2$ - без $\Pi-23$ 


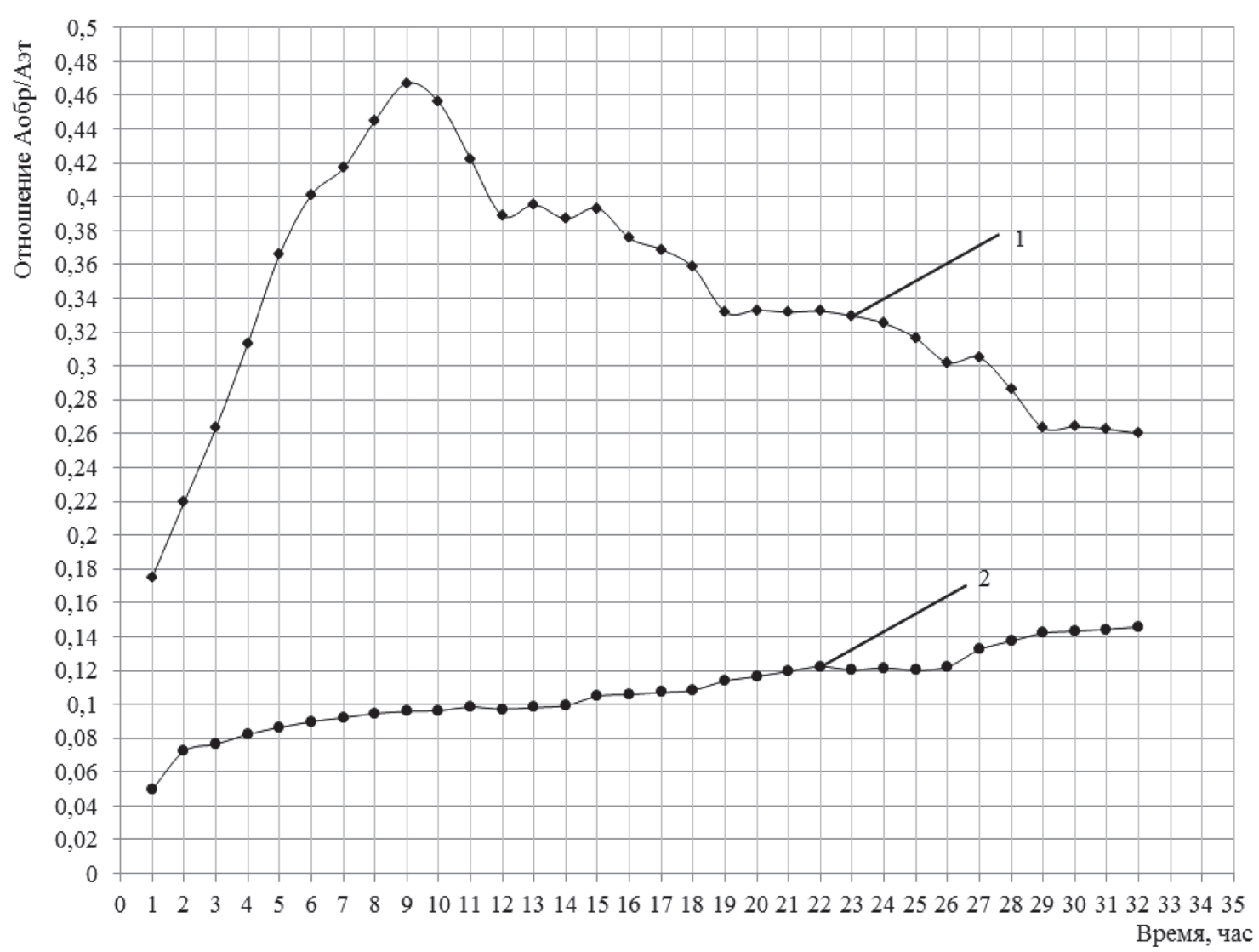

Рис. 3. Кинетика активности системы отверждения БК в присутствии П-23 в зависимости от температуры: $1-n p u 80^{\circ} \mathrm{C}, 2-n p u 55^{\circ} \mathrm{C}$

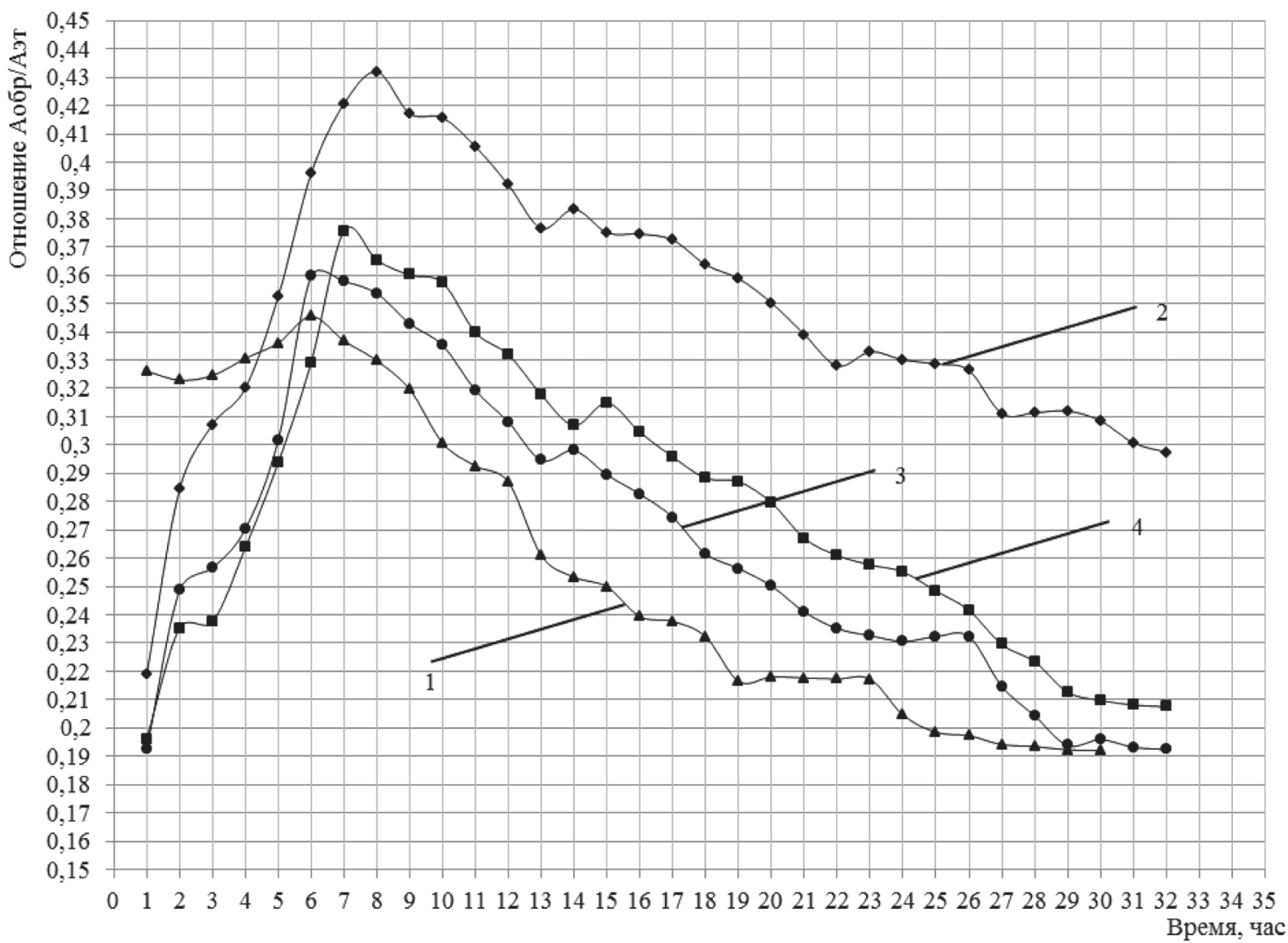

Рис. 4. Кинетика активности системы отверждения БК без П-23 и в его присутствии в разной дозировке при $80^{\circ} \mathrm{C}$ :

$$
1 \text { - без П-23, } 2-1,1 \% ; 3-1,5 \% ; 4-1,8 \%
$$


Далее определяли относительное количество нитрозных радикалов по формуле

$$
K=\frac{A_{\text {обр }}}{A_{\text {эm }}},
$$

где: $A_{\text {обр }}, A_{\text {эт }}$ - амплитуды спектра ЭПР для образца и эталона, которые характеризуют количество образовавшихся радикалов.

Анализ экспериментальных данных, представленных на рис. 1, 2, показал, что при введении в систему отверждения П-23 ингибирующее действие проявляется сразу на первой стадии - при окислении ПХД.

Индукционный период вулканизации БК в присутствии пространственно-затруднённого фенола выше, чем у образцов без фенола.

Важным фактором, влияющим на ингибирующую функцию вещества, является температура. С повышением температуры скорость полимеризации увеличивается, что обусловлено возрастанием скорости инициирования.

По кривым на рис.1,2 видно, что процесс образования и количество нитрозных радикалов при температурах 55 и $80{ }^{\circ} \mathrm{C}$ значительно отличаются друг от друга. Так, при $55^{\circ} \mathrm{C}$ (рис. 3) наблюдаются плавный рост и относительная стабилизация образовавшихся радикалов по истечении 28 часов эксперимента, а при $80{ }^{\circ} \mathrm{C}$ при наличии в системе П-23 по истечении 9 часов достигнут максимум образования радикалов, а затем происходит резкий спад, что свидетельствует об их расходовании.

Образец без П-23 (рис. 4) изначально показал высокий уровень образования радикалов с последующим их расходованием за счёт вулканизации БК. Чем больше введено ингибитора, тем сильнее торможение процесса окисления ПХД двуокисью марганца. Предположительно П-23, являясь акцептором реакции, ингибирует процесс образования п-ДНБ. С увеличением концентрации ингибитора количество образовавшихся нитрозных радикалов уменьшается.

\section{Выводы}

1. Индукционный период вулканизации образцов БК в присутствии П-23 выше, чем у образцов без него.

2. П-23 ускоряет расход ПХД. Чем больше введено ингибитора, тем меньше скорость вулканизации БК.

3. С повышением температуры скорость вулканизации каучука увеличивается, что обусловлено возрастанием скорости инициирования.

\section{Лumepamypa}

1. Фомин B.M. Радикально-цепное окисление органических соединений и его торможение ингибиторами фенольного типа. Учебное пособие. Нижний Новгород: Нижегородский госуниверситет, 2010. 37 с.

2. Аллигер Г., Сьетун И. Вулканизация эластомеров. М., Химия. 1967, гл. 7.

3. Гофман. В. Вулканизация и вулканизирующие агенты. М., Химия. 1968, гл. 12.

4. Эммануэль Н.М., Денисов Е.Т., Майзус 3.К. Цепные реакции окисления углеводородов в жидкой фазе. М.: Наука, 1965. 373 с.

5. Денисов E.T., Эмануэль Н.М. Успехи химии. 1958. T. $27.365 \mathrm{c}$

6. Ершов В.В., Никифоров Г.А., Володькин А.А. Пространственно-затрудненные фенолы. М., Химия. $1972.353 \mathrm{c}$. 